\title{
Biological anthropology
}

SIR - Your report of Roger Bannister's views on the biological basis of exceptional track athletes (Nature 377, 183-184; 1995) characterized biological anthropology as being "under a cloud for its habit of using measurable skeletal indices as proxies for less tangible attributes" such as cranial capacity as a measure of intelligence. It was suggested that this should be replaced by a modern focus centred in the proposed Human Genome Diversity Project (HGDP).

No life science can ignore modern genetics, but the HGDP would at most be a supplement to rather than a replacement for the diverse work of biological anthropologists, which includes palaeontology, growth and development, and behaviour studies, to name but a few. Work in these areas is of contemporary quality, and contributes to our understanding of normal human variation and its origins, a subject too often omitted in biomedical research.

Physical anthropology has not used such indices as cranial capacity as proxies for human intelligence for decades. Indeed, textbooks and instructors in anthropology go out of their way to stress the fallacies and dangers in such usage.

This is an era of rapid discovery of important and wide-ranging new knowledge in genetics. The resulting intense competitiveness can lead to hubris and excessive claims about the power of genes to determine almost any human trait, including socially relevant ones. Unfortunately, this hubris is matched by a class of comparably unrestrained professional critics who exploit the widespread public misunderstanding and fears of genetics to suggest that the study of human genetic variation is almost necessarily sinister. The HGDP has never claimed that the type of genetic data it would collect would be relevant to studies of variation in traits such as athletic performance or intelligence, and certainly not as pertains to 'racial' stereotypes.

On the contrary, properly done studies of human variation, genetic or otherwise, can contribute to a more inclusive, less classificatory understanding of our nature as a species. On the basis of what we already know, one consequence of such studies of genetic diversity will not be to usher in a new era of genetic determinism but to enhance our recognition that human biological phenotypes - such as running ability - are not categorically distributed among different 'races'. Nutrition, habituation (training), growth and development, and cultural aspects of human beings make material contributions to all such traits. This is the routine subject matter of anthropology.

Africans who have been competing successfully in international track and field should be deservedly proud of their efforts. Were this just in their genes, we could simply award Africans a permanent Gold Medal and abandon future Olympic races. That would diminish their achievement, making it seem automatic, a loss to the whole purpose of sport. And it would be bad genetics, as any good biological anthropologist would tell you.

\section{Kenneth M. Weiss}

(Chairman, Biological Anthropology

Section, American Anthropological

Association)

Department of Anthropology,

Pennsylvania State University,

409 Carpenter Building,

University Park,

Pennsylvania 16802-3404, USA

\section{Write to reply}

SIR - In John Maddox's parting leading article (Nature 378, 521-533; 1995), he repeats a theme often sounded before: that scientists are poor writers (or at least that scientific papers are poorly written), and speculates on the reasons. One reason is that we are forced by our colleagues to write obscurely. This is never mentioned in the endless discussions about scientific writing, but it is true nonetheless.

For instance, Strunk and White advise writers, "Use the active voice". Robert Day adds, "Do not be afraid to name the agent of the action in a sentence, even when it is 'I' or 'we"'. Following their advice provoked this response from a referee: "Most of my comments concern writing style. My biggest preoccupation with style is that the paper is written in the first person. This should be avoided whenever possible."

Here is some more advice given to authors: "Every scientist should avoid jargon" (Day). "Shortness is a merit in words" (Fowler). "Avoid fancy words" (Strunk and White). But scientists who have followed it know that their colleagues don't agree. The word "get" in their manuscripts is crossed out and replaced with "obtain" (occasionally with the comment "colloquial" in the margin). "Use" becomes utilize, "method" becomes (usually incorrectly) "methodology", and so on.

The worst sin is liveliness of style. Many scientists are earthy in speech but can't distinguish dignity from pomposity in prose. Lively writing will usually provoke criticism. If you attempt to include an actual JOKE in a scientific paper, you have a major fight on your hands.

Peer pressure can't completely explain why scientific writing has become so dark and dull. One has still to explain how we scientists picked up this dismal habit. But peer pressure can explain why the habit persists. A young scientist who tries to write well gets stamped on. To avoid the risk of inflaming a referee and having a paper rejected, he desists. In time, the belief that "get" is a colloquialism so grows on him that he automatically crosses it out whenever he sees it.

\section{Leon Avery}

Department of Biochemistry, University of Texas,

Southwestern Medical Center,

5323 Harry Hines Blvd,

Dallas, Texas 75235-9038, USA

\section{Joule ratings miss the mark}

SIR - Even without possible fraud (see Nature 377, 281; 1995), the project review procedure of the European Commission (EC)'s Joule programme lacks scientific integrity. Each project proposal seems to be evaluated by some five referees, each giving the project a rating from $\mathrm{A}$ to $\mathrm{N}$. The ratings are then averaged, and applicants may learn their average rating from their national focal points. However, in contrast to other EC programmes, which transmit both rating and some ten lines of reasons for the verdict to each proposer, the Joule programme provides no feedback to applicants.

The procedure used in the Joule programme inevitably leads to the most innovative project proposals being rated $\mathrm{C}$ or below because of differences in the outlooks and preferences of the reviewers. Because there is money only for the Arated projects and perhaps a few B-rated ones, some of the more challenging projects are lost, and it is the least controversial that seem to be supported. The list of funded projects seems to confirm this, as does my personal experience of always getting money for the project proposals about which I was least enthusiastic. It may also explain the incorrect impression of Ezio Andreta, who is in charge of the section of the research commision concerned with non-nuclear energy, that the number of worthy projects is diminishing. (He probably does not see the proposals turned down by the scientific review teams.)

My conjecture may not be valid in more narrow areas of science, but the commission's programme areas are always broad and interdisciplinary. Different schools and skills will therefore rate a particular project differently, and, assuming that the width of the fields is indeed reflected in the choice of referees, the inevitable result will be the loss of many innovative project ideas, which will never achieve a consensus A-rating.

\section{Bent Sørensen}

Roskilde University, Institute 2,

Energy and Envonment Group,

PO Box 260,

DK-4000 Roskilde,

Denmark 